\title{
Correction: The effects of low-calorie sweeteners on energy intake and body weight: a systematic review and meta-analyses of sustained intervention studies
}

\author{
Peter J. Rogers (D) - Katherine M. Appleton (D)
}

Published online: 27 May 2021

(c) The Author(s), under exclusive licence to Springer Nature Limited 2021

Correction to: International Journal of Obesity

https://doi.org/10.1038/s41366-020-00704-2

Since publication of this article, we have discovered errors in the reporting of the results for two analyses in Table 1. For the LCS vs water/nothing comparison for parallelgroups studies, the results for energy intake were incorrectly reported. These results are correctly reported in the table below. These analyses are correctly reported in the text, in the tables in the Supplementary Materials, and are correctly represented in Fig. 3, but the conversion to relevant units in the legend for Fig. 3 should read 'for EI the overall result can be converted to $593(222,963) \mathrm{kJ} /$ day'. For the LCS vs water/nothing comparison for cross-over studies, the analyses for adverse events included 0 studies. These results are correctly reported in the table below. These results are correctly reported in the text. These corrections do not alter the pattern of our results, nor our conclusions. 
Table 1 Summary of the results of the meta-analyses (random effects models), estimates converted to relevant units.

\begin{tabular}{|c|c|c|c|c|c|c|c|c|}
\hline \multirow[t]{2}{*}{ Outcome } & \multicolumn{4}{|c|}{ Parallel-groups studies } & \multicolumn{4}{|c|}{ Cross-over studies } \\
\hline & $N^{\mathrm{a}}$ & $N^{\mathrm{b}}$ & $\begin{array}{l}\text { SMD estimates converted } \\
\text { to relevant units }{ }^{c}\end{array}$ & $I^{2 \mathrm{~d}}$ & $N^{\mathrm{a}}$ & $N^{\mathrm{b}}$ & $\begin{array}{l}\text { SMD estimates converted } \\
\text { to relevant units }{ }^{\mathrm{c}}\end{array}$ & $I^{2 \mathrm{~d}}$ \\
\hline$\Delta \mathrm{BW}, \mathrm{kg}^{\mathrm{e}}$ & 29 & 2267 & $-1.06(-1.50,-0.62)^{* *}$ & 51 & 8 & 123 & $-0.53(-1.01,-0.05)^{*}$ & 0 \\
\hline BWend, kg & 26 & 2196 & $-1.45(-2.50,-0.41)^{*}$ & 0 & 8 & 123 & $-0.55(-5.34,4.25)$ & 0 \\
\hline$\Delta \mathrm{BMI}, \mathrm{kg} / \mathrm{m}^{2}$ & 11 & 1348 & $-0.35(-0.58,-0.12)^{* *}$ & 70 & 2 & & & \\
\hline BMIend, $\mathrm{kg} / \mathrm{m}^{2}$ & 11 & 1348 & $-0.27(-0.63,0.10)$ & 0 & 2 & & & \\
\hline Energy intake, kJ & 22 & 1397 & $-941(-1341,-541)^{* *}$ & 45 & 12 & 149 & $-1304(-2118,-489)^{* * *}$ & 0 \\
\hline Adverse events (OR) & 8 & 1064 & $0.99(0.64,1.53)$ & 0 & 0 & & & \\
\hline$\Delta \mathrm{BW}, \mathrm{kg}^{\mathrm{e}}$ & 11 & 1068 & $0.10(-0.87,1.07)$ & 82 & 4 & 134 & $-0.45(-0.91,0.00)^{*}$ & 0 \\
\hline BWend, kg & 10 & 1040 & $-0.01(-1.55,1.53)$ & 3 & 4 & 134 & $-0.05(-0.50,0.39)$ & 0 \\
\hline$\Delta \mathrm{BMI}, \mathrm{kg} / \mathrm{m}^{2}$ & 8 & 431 & $0.20(-0.10,0.51)$ & 64 & 0 & & & \\
\hline BMIend, $\mathrm{kg} / \mathrm{m}^{2}$ & 8 & 431 & $0.23(-0.40,0.87)$ & 0 & 0 & & & \\
\hline Energy intake, kJ & 10 & 878 & $593(222,963)^{* *}$ & 21 & 3 & 80 & $-431(-1711,850)^{*}$ & 0 \\
\hline Adverse events (OR) & 3 & & & & 0 & & & \\
\hline$\Delta \mathrm{BW}, \mathrm{kg}^{\mathrm{e}}$ & 7 & 521 & $-0.28(-0.80,0.25)$ & 0 & 0 & & & \\
\hline BWend, kg & 7 & 521 & $-0.82(-2.94,1.30)$ & 0 & 0 & & & \\
\hline$\Delta \mathrm{BMI}, \mathrm{kg} / \mathrm{m}^{2}$ & 8 & 486 & $0.20(0.04,0.36)^{*}$ & 0 & 0 & & & \\
\hline BMIend, $\mathrm{kg} / \mathrm{m}^{2}$ & 8 & 486 & $-0.47(-1.07,0.13)$ & 0 & 0 & & & \\
\hline Energy intake, kJ & 0 & & & & 0 & & & \\
\hline Adverse events (OR) & 10 & 786 & $0.83(0.64,1.07)$ & 0 & 0 & & & \\
\hline
\end{tabular}

Results are for energy intake and adverse events measured during the intervention. Where cells are empty no analyses were undertaken due to insufficient numbers of studies.

$L C S$ low-calorie sweeteners, $\triangle B W$ change in body weight, $B W e n d$ body weight at the end of the intervention, $\triangle B M I$ change in body mass index, $B M I e n d$ body mass index at the end of the intervention, $O R$ odds ratio.

$* * P \leq 0.01 ; * P<0.05$.

${ }^{a}$ Number of studies providing data suitable for analysis and included in the analysis.

${ }^{\mathrm{b}}$ Number of participants in the analysis.

${ }^{\mathrm{c}}$ Standardised mean difference and (95\% CIs), converted to relevant units. A minus sign shows an effect in favour of LCS.

${ }^{\mathrm{d}}$ Measure of differences in results between studies (heterogeneity, \%).

${ }^{\mathrm{e}}$ For parallel-groups studies simple linear regression with study duration as the predictor variable was used to estimate missing SDs. For cross-over studies and all other variables, missing SDs were imputed using mean SD. 